\title{
Formulation Development of Losartan Potassium Immediate Release Tablets and Process Optimization using SeDeM Expert System
}

\author{
Imran Tadwee ${ }^{1 *}$, Sadhana Shahi ${ }^{2}$ \\ 'Y.B. Chavan College of Pharmacy Aurangabad-431001, Maharashtra, India. \\ ${ }^{2}$ Government College of Pharmacy Aurangabad-431001, Maharashtra, India.
}

\begin{tabular}{l}
\hline ARTICLE INFO \\
\hline Article history: \\
Received on: 25/12/2017 \\
Accepted on: 29/01/2018 \\
Available online: $27 / 02 / 2018$ \\
\\
\hline Key words: \\
Poor Flow, SeDeM Method, \\
Preformulation, Direct com- \\
pression, Losartan.
\end{tabular}

\section{INTRODUCTION}

Losartan potassium is a competitive AT1 angiotensin II receptor antagonist. Angiotensin II helps to maintain constant blood pressure despite fluctuations in a person's state of hydration, sodium intake and other physiological variables. Angiotensin II also performs the regulatory tasks of inhibiting excretion of sodium by the kidneys, inhibiting norephedrin reuptake and stimulating aldosterone biosynthesis. By inhibiting angiotensin II binding to AT1 receptors, losartan disrupts the vasoconstriction mediated by AT1 receptors. Blocking vasoconstriction by angiotensin II has been found to be beneficial to patients with hypertension (Lifshitz et al., 2004). In preset study losartan potassium immediate release tablet was formulated by using direct compression method.

\footnotetext{
${ }^{*}$ Corresponding Author

Imran Tadwee, Y.B. Chavan College of Pharmacy Aurangabad-431001, Maharashtra, India.E-mail: immit2014@gmail.com
}

As per the literature it was observed that Losartan potassium API having very poor flow (Lifshitz et al., 2004). All the effort was to make this API suitable by direct compression, as in the industries maximum time wet granulation process is used to formulate Losartan potassium tablet, in direct compression case its recommended to employ excipient which has good flow or which are directly compressible grade qualitatively, to incorporate such excipient quantitatively is always a task for the formulator. While developing the formulation it's important to be cautious and specific to select concentration of excipient (mg per tablet) so that they should not become toxic to patient and this can be achieve by accessing inactive ingredient database of USFDA. This gives us information about highest possible level of use (Safe level) of particular excipient as per dosage form and route of administration as well. Qualitative and quantitative formulas mentioned in patent as well as in literature are protected by intellectual property right and restricted to use option remain is to perform trial and error approach. In the current development SeDeM expert system is 
introduced which shows the suitability of API \& excipient for direct compression process also it reveals the $\%$ concentration of excipient or polymer to be incorporated in the formulation so that poor flow characteristic of API will get masked. This optimization tool is well reported in literature as well as in scientific books (Pilar et al., 2006). SeDeM Method used while preformulation studies emphases always on the physical properties of drug substances related to its suitability in the direct compression process. For the present study different excipient is used to correct the API's poor flow and make it suitable for direct compression using SeDeM Method. SeDeM can be termed as Secure Development Method, ICH-Q8 provides a basis for the SeDeM expert system. It is used for an evaluation of critical quality attributes which is a part of Quality by Design which has an impact on the final product. This system provides prediction of flow and a physical profile of drug and excipients intended to be used (Khan et al., 2013). SeDeM expert system may be coined as time saving as this technique may reduce no of trials. Due to the ability of prediction for deficient part this technique may serve as economic and choice of technique compared to other time consuming conventional trial and error approach or software based prediction models.

\section{MATERIALS AND METHOD}

Losartan potassium, Avicel PH 101, Lasctose SD, Maize Starch, Sodium Starch Glycolate and Magnesium Stearate obtained from Wockhardt Pharmaceuticals Ltd Aurangabad, India. All the materials were of pharmaceutical grade.

\section{Preformulation studies}

\section{API confirmation using UV spectrometry}

UV spectrometry was performed in order to confirm the received active pharmaceutical ingredient. The ultraviolet absorption spectrum of Losartan potassium was obtained using Shimadzu 1700-PC UV visible spectrophotometer and $1 \mathrm{~cm}$ quartz cells, over a wavelength range of 400 to $200 \mathrm{~nm}$ in $0.1 \mathrm{~N} \mathrm{HCl}$ solution. The wavelength maxima ( $\lambda$ max) was shown by using UV Probe software. A stock solution was prepared by weighing $10 \mathrm{mg}$ of Losartan Potassium in $100 \mathrm{~mL}$ of volumetric flask and dissolved in Distilled Water to obtain a concentration $0.1 \mathrm{mg} / \mathrm{mL}$ or $100 \mu \mathrm{g} / \mathrm{mL}$ (stock) (Bonfilio, 2010).

\section{API confirmation using FT-IR analysis}

The IR absorbance spectrum of drug was recorded using IR 200 spectrometer (Thermo Electron Corporation) over a range of 400 to $4000 \mathrm{~cm}^{-1}$. The drug sample was directly placed in the sample cell in IR chamber and spectrum was recorded. The obtained graph was analyzed for different functional group using IR solution software version 1.40 (Hemalatha et al., 2011).

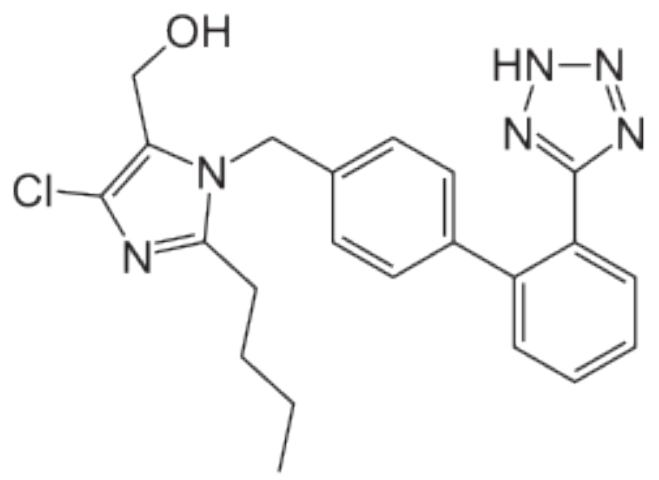

Fig. 1A: Structure of Losartan potassium.

\section{Evaluation of material as per SeDeM expert system}

Powder material including excipient and drug Losartan potassium was evaluated for different parameters according to the SeDeM expert system to determine their suitability for direct compression. Some of them were determined experimentally according to the established procedure and some were calculated from experimental values as per Table 1 (Suñé Negre et al., 2011).

Table 1: Parameters of SeDeM expert system along with limits \& factors.

\begin{tabular}{|c|c|c|c|c|c|}
\hline Incidence Factor & Parameter (Symbol) & Unit & Equation & Limit Value & Conversion factor applied \\
\hline \multirow{2}{*}{ Dimensions } & Bulk Density (Da) & $\mathrm{gm} / \mathrm{ml}$ & $\mathrm{Da}=\mathrm{P} / \mathrm{Va}$ & $0-1$ & $10 \mathrm{v}$ \\
\hline & Tapped Density (Dc) & $\mathrm{gm} / \mathrm{ml}$ & $\mathrm{Dc}=\mathrm{P} / \mathrm{Vc}$ & $0-1$ & $10 \mathrm{v}$ \\
\hline \multirow{3}{*}{ Compressibility } & Interparticle porosity (Ie) & - & $\mathrm{Ie}=\mathrm{DC}-\mathrm{Da} / \mathrm{Dc} \times \mathrm{Da}$ & $0-1.2$ & $10 \mathrm{v} / 1.2$ \\
\hline & Carr index (Icd) & $\%$ & $\mathrm{IC}=(\mathrm{Dc}-\mathrm{Da} / \mathrm{Dc})$ & $0-50$ & $10-(\mathrm{v} / 5)$ \\
\hline & Cohesion index (IC) & $\mathrm{N}$ & Experimental & $0-200$ & $\mathrm{v} / 20$ \\
\hline \multirow{3}{*}{ Powder Flow } & Hausner Ration (IH) & - & $\mathrm{IH}=\mathrm{Dc} / \mathrm{Da}$ & $3-0$ & $10-(10 v / 3)$ \\
\hline & Angle of repose $(\alpha)$ & - & $\mathrm{A}=\tan ^{-1} \mathrm{~h} / \mathrm{r}$ & $50-0$ & $10-(\mathrm{v} / 5)$ \\
\hline & Flowability $\left(\mathrm{t}^{\mathrm{n}}\right)$ & $\mathrm{S}$ & Experimental & $20-0$ & $10-(\mathrm{v} / 2)$ \\
\hline \multirow{2}{*}{ Stability } & Loss on Drying (\% LOD) & $\%$ & Experimental & $10-0$ & $10-\mathrm{v}$ \\
\hline & Hygroscopicity (\% H) & $\%$ & Experimental & $20-0$ & $10-(\mathrm{v} / 2)$ \\
\hline \multirow{2}{*}{ Lubricity } & Particles < 50 m (\% Pf) & $\%$ & Experimental & $50-0$ & $10-(\mathrm{v} / 5)$ \\
\hline & Homogeneity index (IӨ) & - & Eq. (1) & $0-0.02$ & $500 v$ \\
\hline
\end{tabular}

\section{Determination of basic parameters}

The basic parameters of the SeDeM expert system shown in Table 1 are given as below (Suñé Negre et al., 2011).

\section{1) Bulk density (Da)}

Bulk density was calculated in accordance with the method described in Section 2.9.15 of European Pharmacopoeia. 
The total volume in bulk density measurements included particle volume, inter-particle void volume and internal pore volume.

\section{2) Tapped density (Dc)}

Dc was calculated in accordance with the method described in Section 2.9.15 of European Pharmacopoeia. It was determined by applying a controlled packing force to the sample and included the interstitial volume and pore volume in its calculations. Graduated cylinder was employed for density measurements and the volume taken was the value obtained after 2500 strokes using a settling apparatus.

\section{3) Inter-particle porosity (Ie)}

The inter-particle porosity of the drug powder was calculated by the following equation

$$
\mathrm{Ie}=\mathrm{Dc}-\mathrm{Da} / \mathrm{Dc} \times \mathrm{Da} .
$$

\section{4) Carr index (IC\%)} equation

It was computed from Da and Dc using the following

$$
\mathrm{IC}=(\mathrm{Dc}-\mathrm{Da} / \mathrm{Dc}) \times 100 .
$$

\section{5) Cohesion index (Icd)}

The cohesion index was determined by directly compressing the drug powder under study using an eccentric press. The hardness $(\mathrm{N})$ of the obtained tablets was determined andthe mean hardness was calculated.

\section{6) Hausner ratio (IH)}

This was calculated from Da and Dc using the following expression $\mathrm{IH}=\mathrm{Dc} / \mathrm{Da}$.

\section{7) Angle of repose ( $\alpha$ )}

It is the three dimensional angle formed by cone like pile of the material during the determination. The angle of the cone formed was calculated after the product was passed through a funnel with the following dimensions: funnel height $9.5 \mathrm{~cm}$, upper diameter of spout $7.2 \mathrm{~cm}$, internal diameter at the bottom, narrow end of spout $1.8 \mathrm{~cm}$. The funnel was placed on a support at 20 $\mathrm{cm}$ from table surface, centered over a millimeter-grid sheet on which two intersecting lines were drawn, crossing at the Centre. The narrow end of the funnel spout was plugged and the funnel was filled with the product under study until it was flushed with the top end of the spout when smoothed with a spatula. Thereafter, the plug was removed and the powder was allowed to fall onto the millimeter sheet. The radius of the cone base was measured with a slide caliper and the mean value (r) was calculated. Additionally, the cone height $(\mathrm{h})$ was measured and the angle tangent value $(\alpha)$ of the cone was calculated employing the following equation: $\tan$ $\alpha=\mathrm{h} / \mathrm{r}$.

\section{8) Flowability (tn)}

The flow rate described herein as flowability was determined in accordance with the method described in Section 2.9.16-2 of European Pharmacopoeia as the time for a fixed amount of powder to flow through a glass tunnel with $0.85 \mathrm{~cm}$ orifice diameter. It was expressed in seconds and tenths of a second per 100 grams of sample, with the mean value of three determinations always being taken.

\section{9) Loss on drying (\% HR)}

This is determined by the loss on-drying test carried out in accordance with General method 2.2.32 in European Pharmacopoeia. Excipient was dried in a convection oven at $105^{\circ} \mathrm{C} \pm 2^{\circ} \mathrm{C}$ until a constant weight is obtained.

\section{0) Hygroscopicity (\% H)}

The hygroscopicity of a powder is its equilibrium moisture content after being exposed to air humidity under given conditions. It was determined by calculating the increase in sample weight after being kept in a humidifier at ambient relative humidity of $76 \% \pm 2 \%$ and a temperature of $22^{\circ} \mathrm{C} \pm 2{ }^{\circ} \mathrm{C}$ for $24 \mathrm{~h}$.

\section{1) Percentage of particles measuring $<50 \mu(\%$ Pf)}

Particle size was determined by means of the sieve test in accordance with the General method 2.9.12 of European Pharmacopoeia (14) and was expressed as the \% of particles that pass through a $0.05 \mathrm{~mm}$ sieve (ASTM\#270), when vibrated for 10 min at speed 10 using a sieve vibrator.

\section{2) Homogeneity index (It)}

The method for determination of $\mathrm{I} \theta$ was based on General method 2.9.12 of European Pharmacopoeia for determining particle size by means of the sieve test (Singh and Kumar 2012; Shahi and Tadwee 2017). The grain size of a $100 \mathrm{~g}$ sample was determined by submitting a sieve stack to vibration for $10 \mathrm{~min}$ at the speed 10 using a sieve vibrator. Sieve sizes used were: $0.355,0.212,0.100$ and $0.05 \mathrm{~mm}$. (ASTM\#45, \#70, \#140 $\# 270$ respectively). The percentage of product retained in each sieve and the quantity that passes through the $0.05 \mathrm{~mm}$ sieve were calculated. The percentage of fine particles $(<50 \mu)$ determined previously in a separate operation was considered. The following equation was then applied to the data obtained:

$$
I \theta=\frac{F_{m}}{100+\left(d_{m}-d_{m-1}\right) F_{m-1}+\left(d_{m+1}-d_{m}\right) F_{m+1}+\left(d_{m}-d_{m-2}\right) F_{m-2}+\ldots \ldots . .+\left(d_{m}-d_{m-n}\right) F_{m-n}+\left(d_{m+n}-d_{m}\right) F_{m+n}}
$$

Where $\mathrm{I} \theta=$ relative homogeneity index; $\mathrm{F}_{\mathrm{m}}=$ percentage of particles in the majority range; $\mathrm{F}_{\mathrm{m}-1}=$ percentage of particles in the range immediately below the majority range; $\mathrm{F}_{\mathrm{m}+1}=$ percentage of particles in the range immediately above the majority range; $\mathrm{n}$ $=$ order number of the fraction under study, within a series, with respect to the majority fraction; $d_{m}=$ the mean diameter of particles in the majority fraction; $d_{m-1}=$ the mean diameter of particles in the fraction of the range immediately below the majority range; $\mathrm{d}_{\mathrm{m}+1}=$ mean diameter of the particles in the fraction of the range immediately above the majority range (Tadwee et al., 2017). 


\section{Conversion of experimental values (V) to radius value of sedem diagram}

The numerical values for different parameters of the material obtained by experimental determination were converted into a radius value ' $r$ ' of the SeDeM expert system diagram. For the conversion of experimental value of each parameter, specific factors were applied ${ }^{4}$ as listed in Table 1 (Suñé Negre et al., 2011).

\section{Graphical presentation of SeDeM diagram}

SeDeM diagram was drawn on the basis of 12 parameters. Results obtained from the experimental determination of various parameters were converted and presented as a SeDeM diagram (Díaz et al., 2009) as shown in Figure 1b (Suñé Negre et al., 2011).

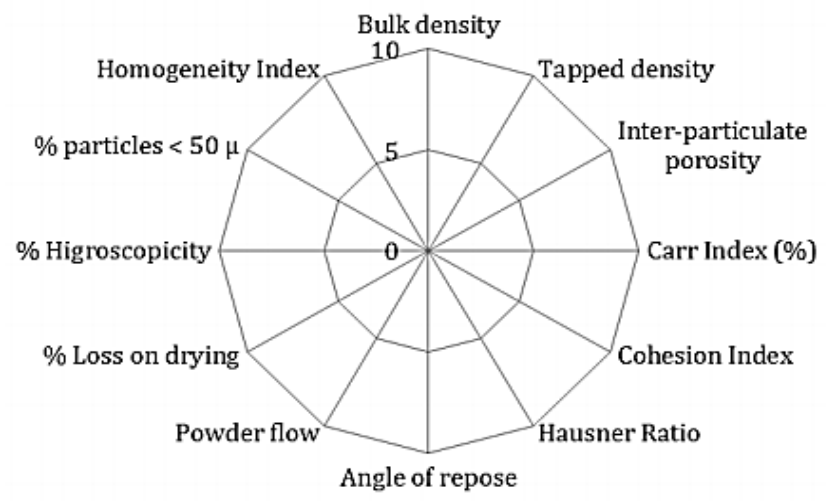

Figure 1b: SeDeM diagram.

\section{Calculation of acceptance values}

For determination of suitability of the material for direct compression the following indices are calculated on the basis of the SeDeM system as below (Suñé Negre et al., 2011).

\section{1) Parameter index}

$$
\text { I.P. }=\text { No. } P \geqslant 5 \text { No. } P t
$$

Where No. $\mathrm{P} \geqslant 5=$ Parameters with values equal to or more than 5 ; No. $\mathrm{Pt}=$ Total number of parameters.

Acceptability limit corresponds to a score of 5.

\section{2) Parameter profile index}

I.P.P. $=$ Average of $\mathrm{r}$ value of all parameters

The acceptable limit corresponds to a score of 5 .

3) Good compressibility index

$$
\text { I.G.C. }=\text { I.P.P. } \times \mathrm{f}
$$

Where $\mathrm{f}=$ Reliability factor $(0.952)$.

\section{Application of SeDeM method to determine the amount of excipient required for the direct compression process for deficient API (Suñé Negre et al., 2011)}

Determination of amount of excipient required to correct the deficiency of poor flow API can be obtained using equation
(3), this equation can be applied to 5 parameters, (Dimension, compressibility, flowability).

This equation allows calculation of the amount of excipient required to compress the API on the basis of the SeDeM radius considering 5 ( $\mathrm{min}$ ) for each parameter of incidence which allows correct compression

$$
\mathrm{CP}=100-[(\mathrm{RE}-\mathrm{R}) /(\mathrm{RE}-\mathrm{RP}) \times 100]
$$

Where $\mathrm{CP}=\%$ Corrective Excipient; $\mathrm{RE}=$ meanincidence radius value (compressibility) of the corrective excipient; $\mathrm{R}=$ mean-incidence radius value to be obtained in the blend; $\mathrm{RP}=$ mean-incidence radius value (compressibility) of the API to be corrected.

In this calculations unknown values were replaced by the calculated ones required for each substance in order to obtain $\mathrm{R}=5$ ( 5 is the minimum value considered necessary to achieve satisfactory compression). For example, if a deficient compressibility parameter for an API requires correction, Equation (3) is applied by replacing the terms RE and RP with the values calculated for each substance with the purpose to obtain a $\mathrm{R}=5$, thus obtaining the optimal excipient to design a first drug formulation and the maximum amount required for a comprehensive understanding of the proposed formula. From this first formulation, research can get underway for the final optimization of the formulation, taking into consideration the biopharmaceutical characteristics required in the final tablet (disintegration, dissolution, etc.) (Suñé Negre et al., 2011).

\section{Formula composition}

Based on the radius values obtained on API \& excipient as well as $\%$ corrective excipient requirement formulation $\mathrm{F} 1$ to F3 derived \& presented in Table 2.

Table 2: Formulation composition.

\begin{tabular}{ccccc}
\hline Sr. No & Name of Ingredient & F1 & F2 & F3 \\
\hline 1 & Losartan Potassium & 25 & 25 & 25 \\
2 & Microcrystalline cellulose (Avicel pH 101) & 70 & - & - \\
3 & Lactose SD & - & 40 & - \\
4 & Maize Starch & $2 *$ & $32^{*}$ & 72 \\
5 & Sodium Starch Glycolate & 2 & 2 & 2 \\
6 & Magnesium Stearate & 1 & 1 & 1 \\
& Total Tablet weight & 100 & 100 & 100 \\
\hline
\end{tabular}

* In order to maintain tablet weight $100 \mathrm{mg}$ maize starch used as filler (Rowe 2009) as maize starch was having average radius value 5.46 which is close to standard radius value 5 .

\section{Preparation of lubricated blend}

Formulation wise all ingredient in the composition were dispensed as per the batch size of 5000 tablets, API potency calculated as per below formula and respective compensation was considered while dispensing for batch manufacturing (g/batch).

$$
\text { API Potency }=\text { Assay on anhydrous basis } \times(100-\text { water }) / 100
$$

Losartan potassium, Microcrystalline cellulose, Lactose SD, Sodium Starch glycolate were sifted through ASTM\#40 and loaded in double cone blender having capacity 2 Liter and blended for $10 \mathrm{~min}$ for $20 \mathrm{rpm}$, further Magnesium stearate sifted through 
ASTM\#60 and loaded in blender and blended for $5 \mathrm{~min}$ at $20 \mathrm{rpm}$.

\section{Blend evaluation using SeDeM}

Obtained blend were subjected to 12 test of SeDeM as per Table 1, result obtained were calculated for radius values, on the basis of radius values SeDeM diagram was plotted, acceptance values were calculated using equations (1), (2) \& (3) composition whose blend yielding higher IPP value (mean $r$ of all parameters) was considered as optimized batch for further evaluation (Suñé Negre et al., 2011; Tadwee et al., 2017).

\section{Tablet compression \& evaluation}

Optimized blend was compressed using $6.5 \mathrm{~mm}$ round beveled edges punch having plain surface on both sides. Compressed tablets were subjected to in process quality control (IPQC) tests (DT, thickness, hardness, and weight variation).

Physical properties of coated and uncoated tablets were evaluated as per the procedures reported in official Pharmacopoeias, as under.

\section{a) Tablet weight}

Weight was calculated after measuring 20 tablets individually using a digital balance (Sartorius). Average weight of 20 tablets were reported in Table 7.

\section{b) Thickness \& diameter}

The thickness and diameter of 10 tablets from each formulation was measured using a Vernier caliper (Digimatic) and their average thickness and diameter reported in Table 7.

\section{c) Hardness test}

Crushing strength of 10 tablets one after another of optimized formulation, was determined using a tablet hardness tester (Dr. Schleuniger) \& mean values were calculated and reported in Table 7.

\section{d) Friability test}

Friability was determined according to official monograph using single drum friabilator (Electrolab). Final \% friability is reported in Table 7.

\section{e) Disintegration test (DT)}

Disintegration test performed as per USP apparatus (Electrolab) on 6 tablets, DT is reported in Table 8.

\section{Tablet coating $\&$ evaluation}

In order to protect from moisture and other environmental factor, compressed tablets were coated using Opadry Clear ${ }^{\circledR}$ Coating ready-mix manually in rolling coating pan, $5 \% \mathrm{w} / \mathrm{W}$ coating solution prepared, tablet were coated up to $2 \%$ weight gain $\left(2 \mathrm{mg}\right.$ ), and curing done at $45^{\circ} \mathrm{C}$ bed temp for $15 \mathrm{~min}$. Coated tablets were subjected to routine IPQC test as per Table 7 .

\section{Assay}

Losartan potassium content of tablets was determined as per the official method described in Pharmacopoeia. Absorbance of the sample solution and standard solution was measured at Mode: LC, Detector: UV $250 \mathrm{~nm}$, Column: 3.9-mm × 15-cm; 5- $\mu \mathrm{m}$ packing L7, Flow rate: $1.0 \mathrm{~mL} / \mathrm{min}$. Injection volume: $10 \mu \mathrm{L}$. The drug content was calculated by a comparison of absorbance of two solutions. All determinations were made in triplicate and their average was calculated. Injection volume was $10 \mu \mathrm{L}$ (USP-NF 37).

\section{Dissolution}

As per the OGD recommendation of USP monograph for dissolution of losartan potassium tablet, dissolution studies were carried out using water as dissolution medium, apparatus 2, $50 \mathrm{rpm}$, aliquots were withdrawn at 5, 10, 15, 30, 45 and $60 \mathrm{~min}$. $\%$ drug release were estimated using UV spectrometry. f1\& f2 value were calculated and shown in Table 7 (USP-NF 37).

\section{Stability study}

Optimized formulation were exposed at room temperature, $40^{\circ} \mathrm{C} / 75 \%$ Relative Humidity, and $30^{\circ} \mathrm{C} / 65 \%$ Relative Humidity for 6 months. The tablets were withdrawn for analysis of following parameters \& results reported in Table 10 (ICH Guidelines Q1A (R2) 2003).

$\begin{array}{ll}\text { 1. } & \text { Average weight } \\ \text { 2. } & \text { Hardness } \\ \text { 3. } & \text { Disintegration time (D. T.) } \\ \text { 4. } & \text { Moisture content } \\ \text { 5. } & \text { Assay. }\end{array}$

\section{RESULT \& DISCUSSION}

\section{Preformulation studies}

\section{API Confirmation through UV}

UV spectra of Losartan potassium exhibited wavelength maxima at wavelength $205 \mathrm{~nm}$, which complies with the reported literature value $205 \mathrm{~nm}$ (Bonfilio, 2010), with this we may confirm that received chemical is losartan potassium.

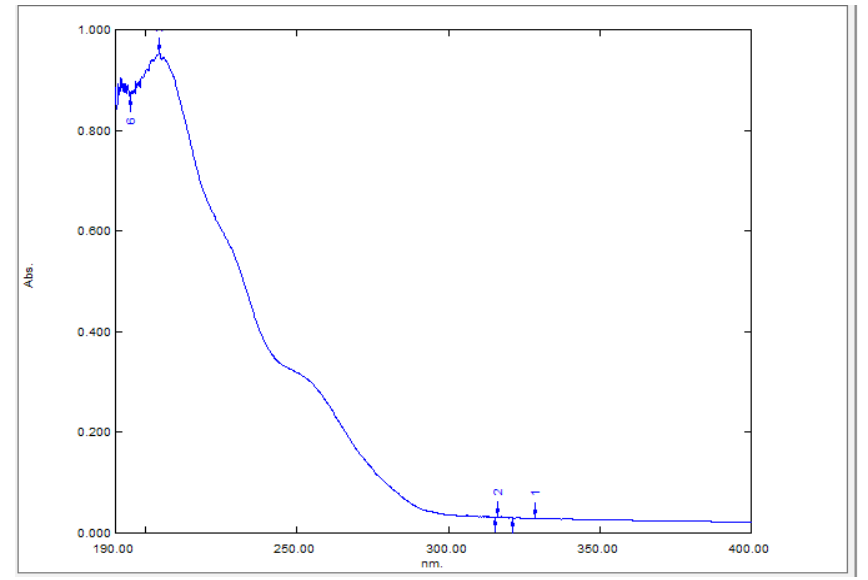

Fig. 2: UV spectrum of losartan potassium.

\section{API confirmation through IR}

FTIR interpretation revealed that the observed frequency with respect to vibration/stretch matches with the structure of losartan potassium. Hence this may be considered that obtained drug is losartan potassium. 
Table 3: FT-IR interpretation for losartan potassium.

\begin{tabular}{cccc}
\hline Sr no & Observed frequency & Type of vibration & Frequency \\
\hline 1 & $2954.95 \mathrm{~cm}^{-1}$ & $\mathrm{C}-\mathrm{H}$ stretch & $3000-2850 \mathrm{~cm}^{-1}$ \\
2 & $1577.77 \mathrm{~cm}^{-1}$ & $\mathrm{NH}$ & $1640-1550 \mathrm{~cm}^{-1}$ \\
3 & $1259.55 \mathrm{~cm}^{-1}$ & $\mathrm{C}-\mathrm{N}$ & $1350-1000 \mathrm{~cm}^{-1}$ \\
4 & $765.74 \mathrm{~cm}^{-1}$ & $\mathrm{C}-\mathrm{Cl}$ & $785-540 \mathrm{~cm}^{-1}$ \\
5 & $1460.11 \mathrm{~cm}^{-1}$ & $\mathrm{CH}_{2}$ bend & $1465 \mathrm{~cm}^{-1}$ \\
6 & $3650 \mathrm{~cm}^{-1}$ & $\mathrm{OH}$ & $3650-3600 \mathrm{~cm}^{-1}$ \\
\hline
\end{tabular}

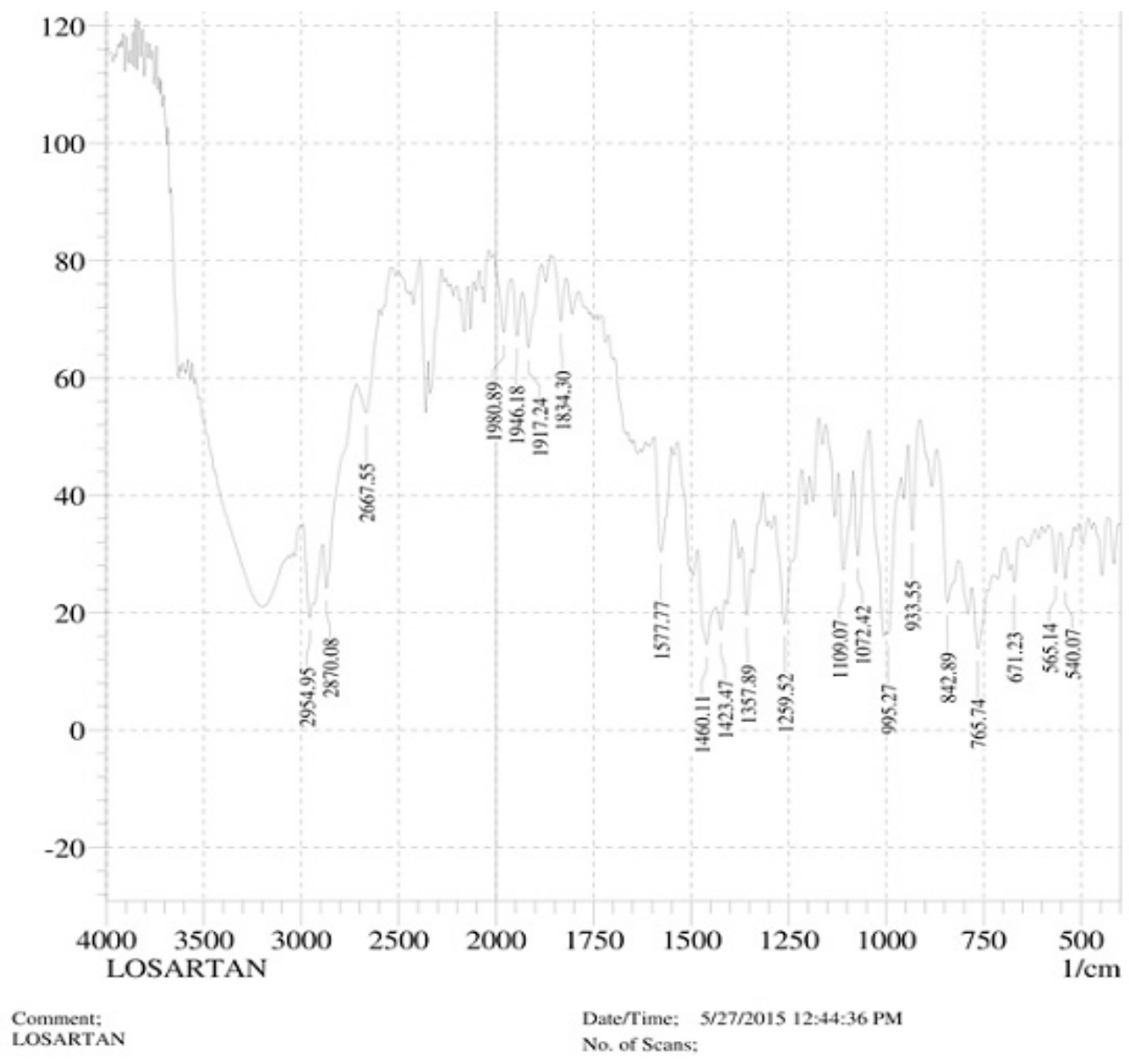

Fig. 3: IR spectrum of losartan potassium.

Table 4: Radius parameters, mean incidence and parametric index for API \& excipients.

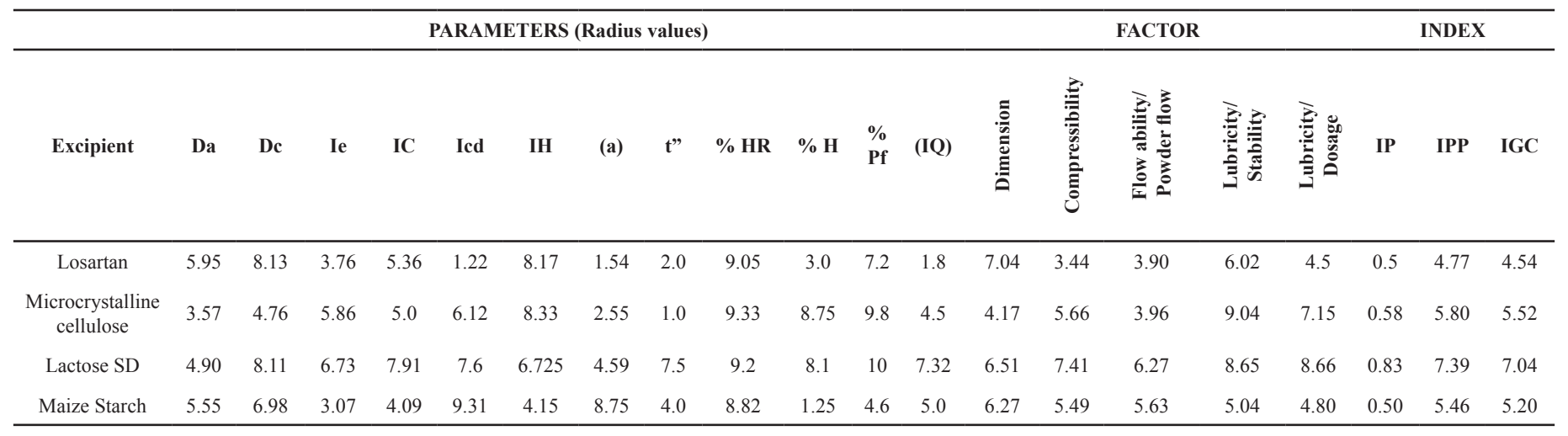




\section{Excipients evaluation using SeDeM method}

Each SeDeM treated excipients were calculated for radius value of 12 test, IP, IPP and IGC value. Result obtained are showed in Table 4.

\section{Determination of amount of corrective excipient required}

As per the outcome of SeDeM radius values and graphs required amount of excipient is calculated using equation no 3. Result obtained is shown in Table 5.

\section{Blend evaluation using SeDeM diagram}

All 3 formulation blend was further processed through SeDeM parameters in order to finalized optimized formulation, values reported in Table 6.

Table 5: Amount of excipient required to be mixed with API in order to obtain compressibility factor equal to 5.

\begin{tabular}{|c|c|c|c|}
\hline Excipient & Microcrystalline Cellulose & Lactose SD & Maize Starch \\
\hline RE & 5.66 & 7.41 & 5.49 \\
\hline RP (API) & 3.44 & 3.44 & 3.44 \\
\hline $\mathrm{R}$ & 5 & 5 & 5 \\
\hline$\%$ Excipient $(\mathrm{CP})$ & 70.27 & 39.29 & 76.09 \\
\hline
\end{tabular}

Table 6: Radius parameters, mean incidence and parametric index for ready to compress blend.

\begin{tabular}{|c|c|c|c|c|c|c|c|c|c|c|c|c|c|c|c|c|c|c|c|c|}
\hline \multirow[b]{2}{*}{$\begin{array}{l}\text { Formula- } \\
\quad \text { tion }\end{array}$} & \multicolumn{12}{|c|}{ PARAMETERS (Radius values) } & \multicolumn{5}{|c|}{ FACTOR } & \multicolumn{3}{|c|}{ INDEX } \\
\hline & Da & Dc & Ie & IC & Icd & IH & (a) & t" & $\begin{array}{c}\% \\
\text { HR }\end{array}$ & $\begin{array}{l}\% \\
\mathrm{H}\end{array}$ & $\begin{array}{l}\% \\
\text { Pf }\end{array}$ & (IQ) & 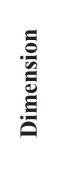 & 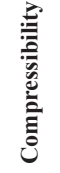 & 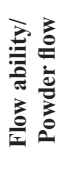 & 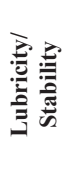 & 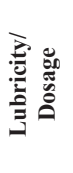 & IP & IPP & IGC \\
\hline $\mathrm{F} 1$ & 4.15 & 5.10 & 3.98 & 3.92 & 7.8 & 8.78 & 2.27 & 5.50 & 7.80 & 7.25 & 4.25 & 7.5 & 4.63 & 5.23 & 5.51 & 7.52 & 5.87 & 0.58 & 5.69 & 5.42 \\
\hline $\mathrm{F} 2$ & 3.85 & 4.95 & 4.82 & 4.44 & 5.85 & 8.57 & 5.55 & 7.00 & 8.05 & 8.05 & 9.5 & 9.5 & 4.40 & 5.14 & 7.04 & 8.05 & 9.50 & 0.67 & 6.68 & 6.36 \\
\hline F3 & 5.56 & 6.58 & 2.32 & 3.10 & 6.62 & 9.08 & 3.48 & 4.50 & 8.25 & 5.37 & 7.5 & 5.5 & 6.07 & 4.01 & 5.68 & 6.81 & 6.50 & 0.67 & 5.66 & 5.38 \\
\hline
\end{tabular}

\section{SeDeM diagrams}

\section{A) Losartan potassium}

See Figure 4.

B) Microcrystalline cellulose

See Figure 5.

C) Lactose $S D$

See Figure 6.

D) Maize starch

See Figure 7.

E) Flow masking of Losartan with Lactose SD

See Figure 8.

F) SeDeM diagram of F1 formulation

See Figure 9.

G) SeDeM diagram of F2 formulation
See Figure 10.

H) SeDeM diagram of F3 formulation

See Figure 11.

In process quality control (IPQC) results

See Table 7.

\section{Determination of assay and dissolution}

Results obtained after evaluation of Losartan potassium formulation for assay and dissolution test was tabulated in Tables $8 \& 9$.

\section{Stability study}

Stability studies of the optimized losartan potassium tablet (formulation F2) was carried out at various atmospheric conditions like room temperature, $40^{\circ} \mathrm{C} / 75 \% \mathrm{RH}, 30^{\circ} \mathrm{C} / 65 \% \mathrm{RH}$ and $25^{\circ} \mathrm{C} / 60 \% \mathrm{RH}$. Even after the period of six month exposure at various atmospheric conditions different stability parameters like average weight, hardness, dissolution time, moisture content, and drug content (assay) were satisfactory (Table 7). Thus, these results confirmed that the optimized losartan potassium tablet (formulation F2) was stable enough. 
SeDeM Diagram: Losartan Potassium (API)

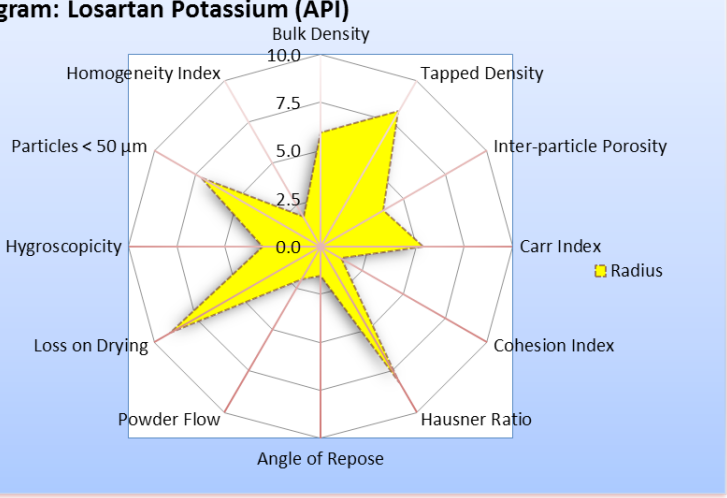

Fig. 4: SeDeM diagram of losartan potassium (API).

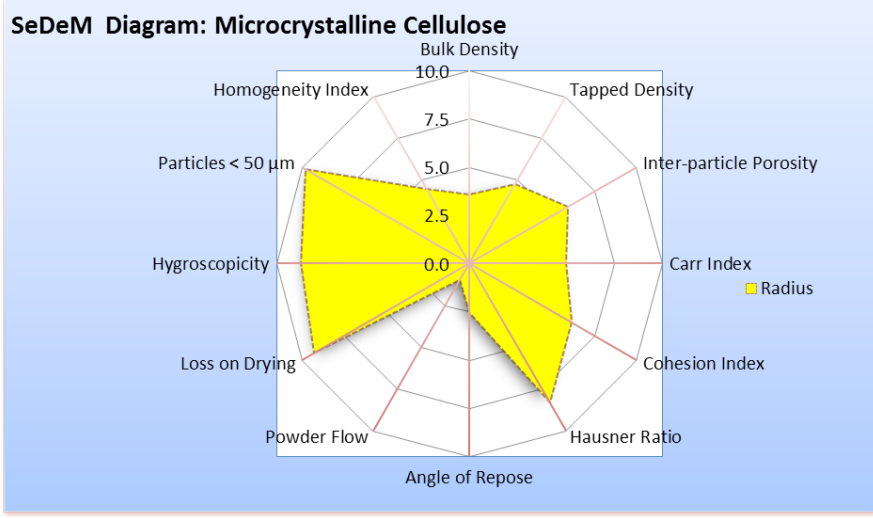

Fig. 5: SeDeM diagram of microcrystalline cellulose.

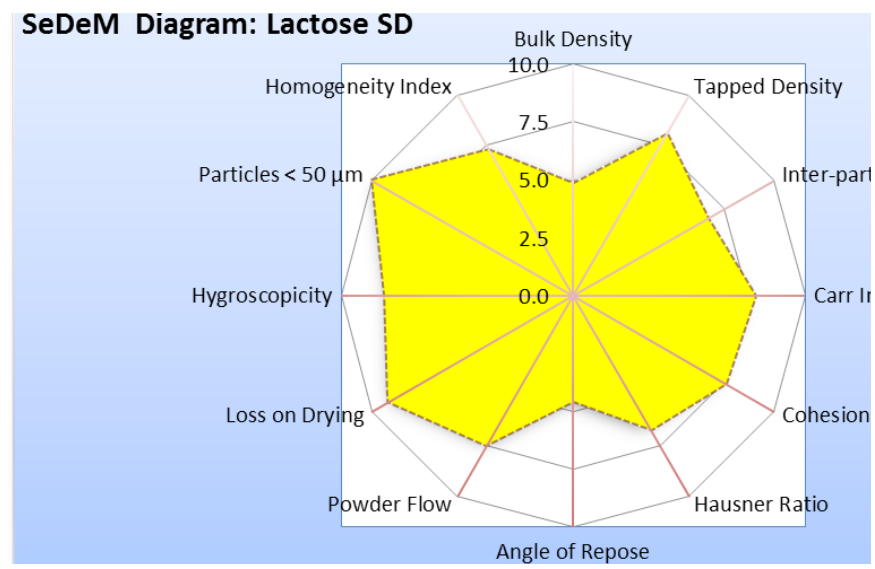

Fig. 6: SeDeM diagram of lactose SD.

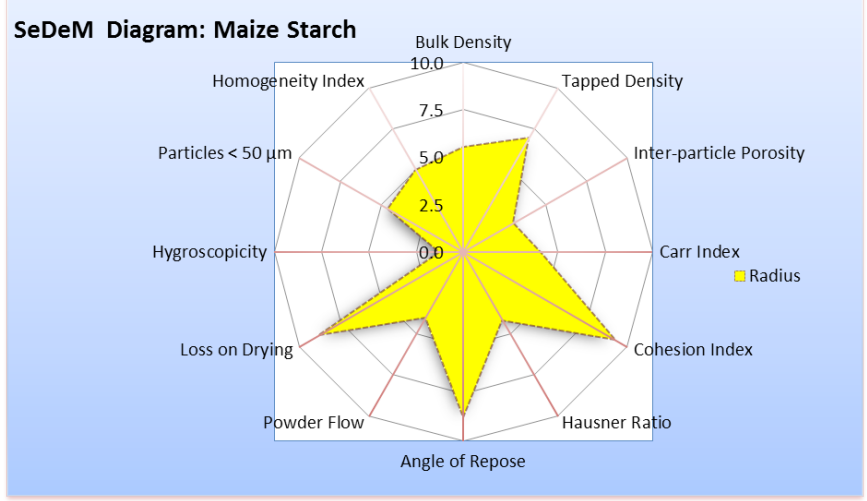

Fig. 7: SeDeM diagram of maize starch.

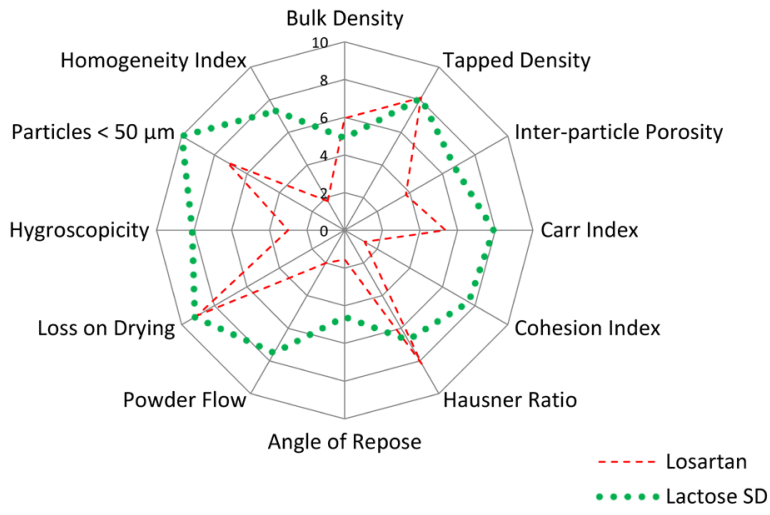

SeDeM Diagram API Flow Masking by Excipient

Fig. 8: Representation of API flow masking using SeDeM diagram.

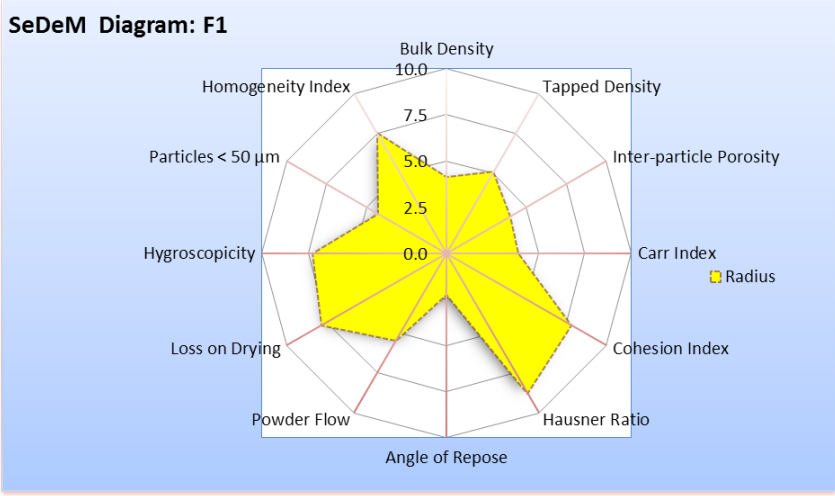

Fig. 9: SeDeM diagram of F1 formulation. 

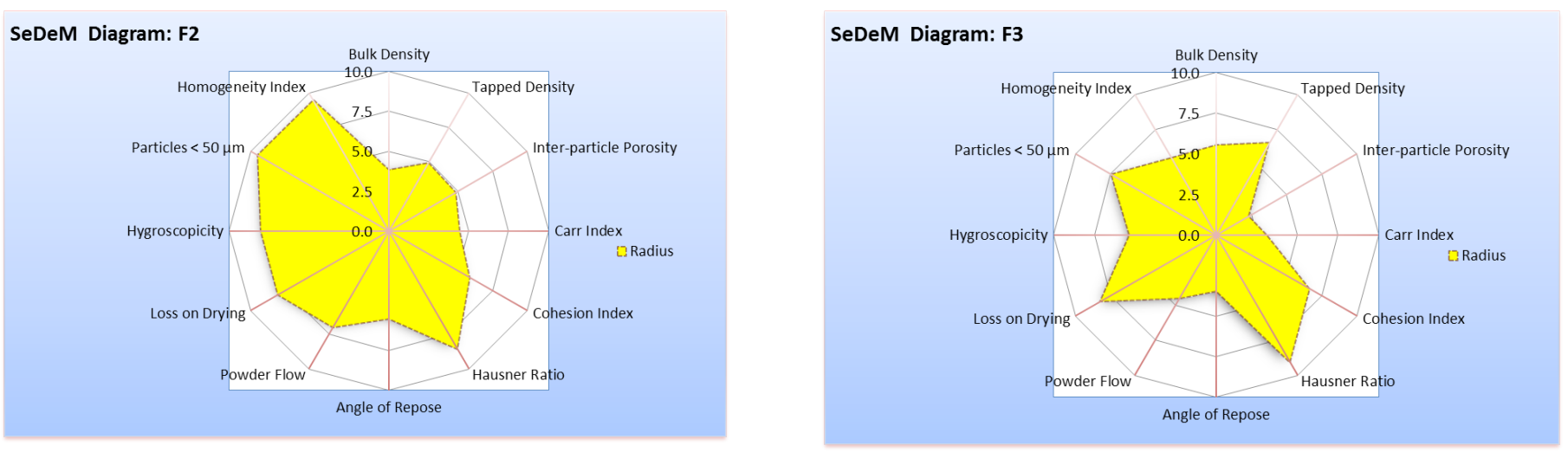

Fig. 10: SeDeM diagram of F2 formulation.

Fig. 11: SeDeM diagram of F3 formulation.

Table 7: IPQC evaluation of coated and uncoated tablet of f1 composition and comparative evaluation using marketed product.

\begin{tabular}{|c|c|c|c|c|c|}
\hline Sr. No & Test & USP monograph Limit & $\begin{array}{l}\text { Losacar Tablet } \\
\text { (Marketed Sample) } \\
\text { Mfg. By: Zydus }\end{array}$ & $\begin{array}{c}\text { F2 } \\
\text { (Uncoated tablet) }\end{array}$ & $\begin{array}{c}\text { F2 } \\
\text { (Coated tablet) }\end{array}$ \\
\hline 1 & Description & NA & $\begin{array}{l}\text { White round film coated tablet im- } \\
\text { printed with Z25 at one side and plain } \\
\text { surface on other side }\end{array}$ & $\begin{array}{l}\text { White round uncoated tablet } \\
\text { having plain surface on both } \\
\text { side }\end{array}$ & $\begin{array}{l}\text { White round film coated tablet } \\
\text { having plain surface on both side }\end{array}$ \\
\hline 2 & Tablet weight $(\mathrm{n}=20)$ & $\begin{array}{c} \pm 10 \% \\
(90-110 \mathrm{mg})\end{array}$ & $99 \mathrm{mg}$ & $99.5 \mathrm{mg}$ & 101.9 \\
\hline 3 & Thickness $(\mathrm{n}=10)$ & NA & $2.92 \mathrm{~mm}$ & $2.95 \mathrm{~mm}$ & 3.03 \\
\hline 4 & Diameter $(\mathrm{n}=10)$ & NA & 6.51 & 6.50 & 6.53 \\
\hline 5 & $\begin{array}{l}\text { Disintegration Time } \\
\left.\text { (in water at } 37^{\circ} \mathrm{C}\right)(\mathrm{n}=6)\end{array}$ & NMT 15 min & $6 \mathrm{~min} 30 \mathrm{sec}$ & $5 \mathrm{~min}$ & $7 \mathrm{~min}$ \\
\hline 6 & $\begin{array}{l}\text { Friability } \\
\text { (20 tablet) }\end{array}$ & NMT 1\% & $0.3 \%$ & $0.25 \%$ & $0.1 \%$ \\
\hline 7 & $\begin{array}{l}\text { Hardness } \\
(\mathrm{n}=10)\end{array}$ & NA & $5.1 \mathrm{kp}$ & $4.5 \mathrm{kp}$ & $5.5 \mathrm{kp}$ \\
\hline
\end{tabular}

Table 8: Comparative assay and dissolution values of optimized formulation with marketed products.

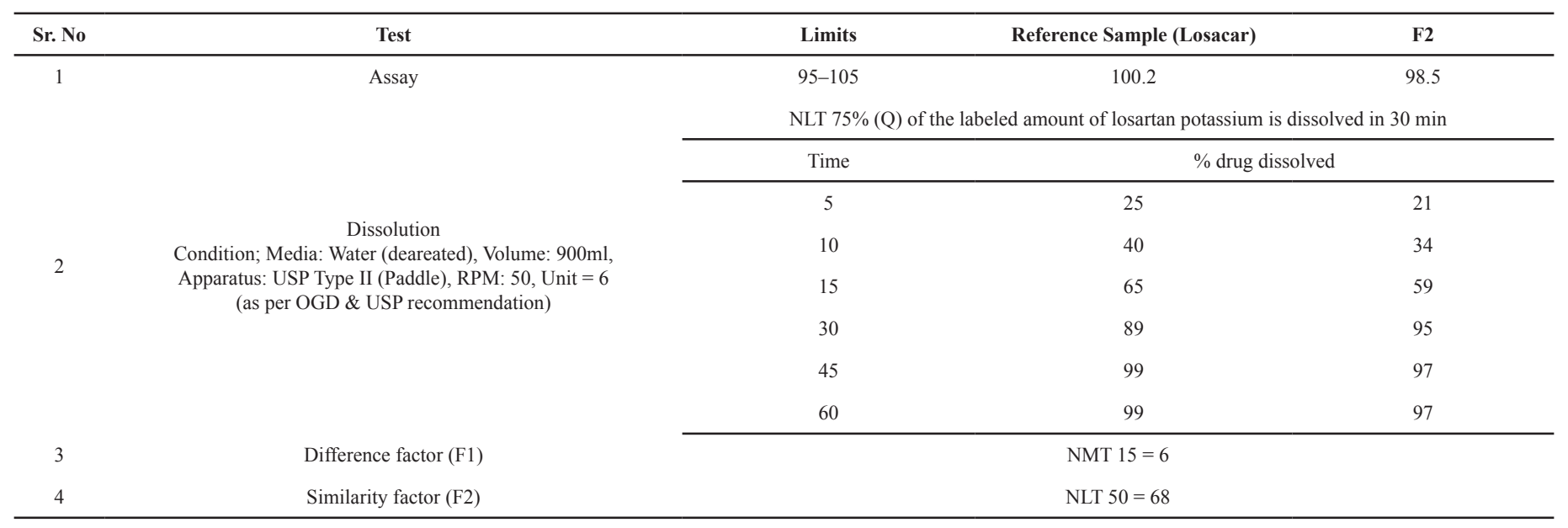


Table 9: Multimedia dissolution of marketed product and optimized formulation.

\begin{tabular}{|c|c|c|c|c|c|c|}
\hline Time point & \multicolumn{2}{|c|}{ Dissolution in pH 1.2} & \multicolumn{2}{|c|}{ Dissolution in pH 4.5} & \multicolumn{2}{|c|}{ Dissolution in pH 6.8} \\
\hline \multicolumn{7}{|c|}{ Condition: Volume: 900ml, Apparatus: USP Type II (Paddle), RPM: 50, Unit $=6$} \\
\hline Time & Losacar & F2 & Losacar & F2 & Losacar & F2 \\
\hline 5 & 5 & 6 & 10 & 12 & 30 & 35 \\
\hline 10 & 7 & 12 & 16 & 18 & 41 & 49 \\
\hline 15 & 12 & 18 & 22 & 21 & 58 & 61 \\
\hline 30 & 16 & 21 & 35 & 29 & 69 & 78 \\
\hline 45 & 22 & 28 & 45 & 38 & 88 & 95 \\
\hline 60 & 35 & 36 & 55 & 49 & 98 & 99 \\
\hline
\end{tabular}

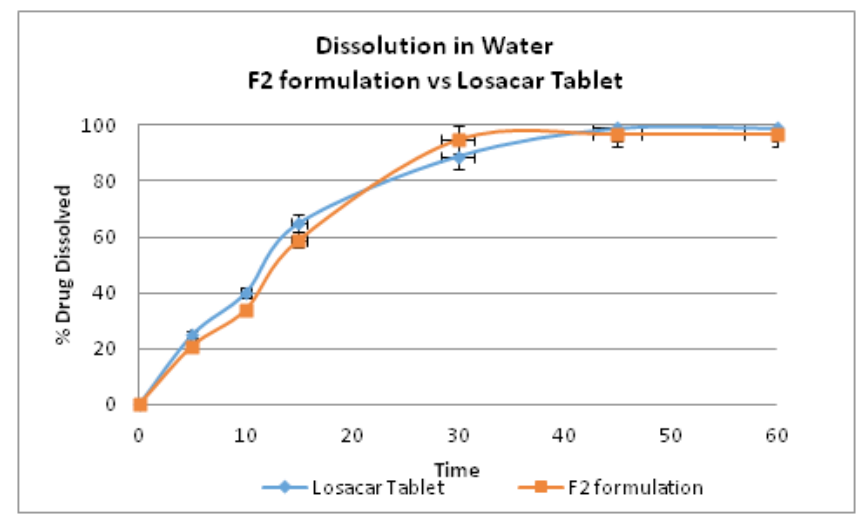

Fig. 12: Dissolution study in water and comparison with marketed product.

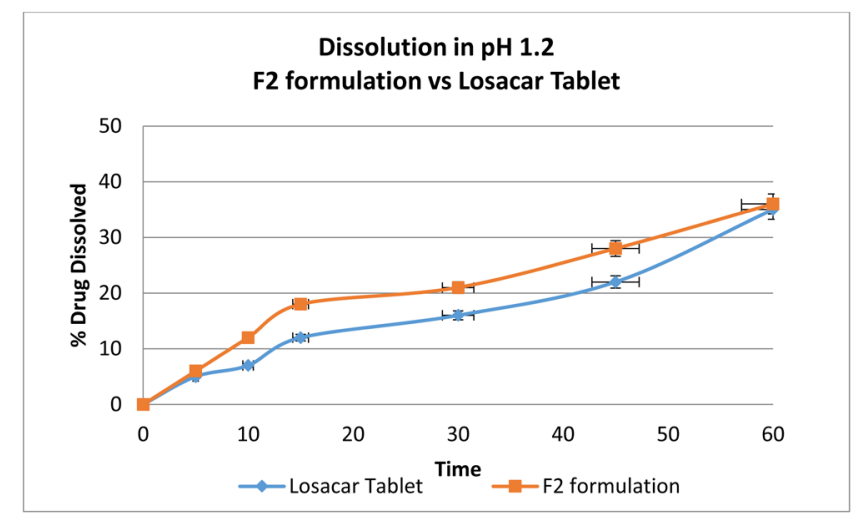

Fig. 13: Dissolution study in $\mathrm{pH} 1.2$ and comparison with marketed product.

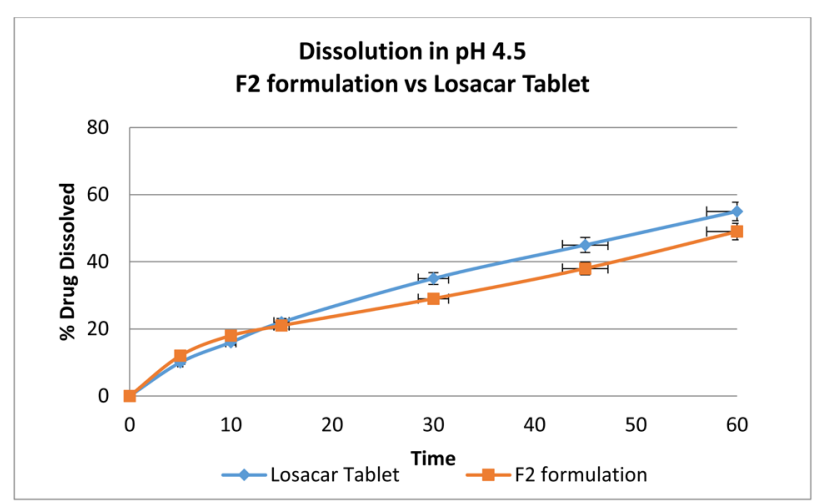

Fig. 14: Dissolution study in $\mathrm{pH} 4.5$ and comparison with marketed product.

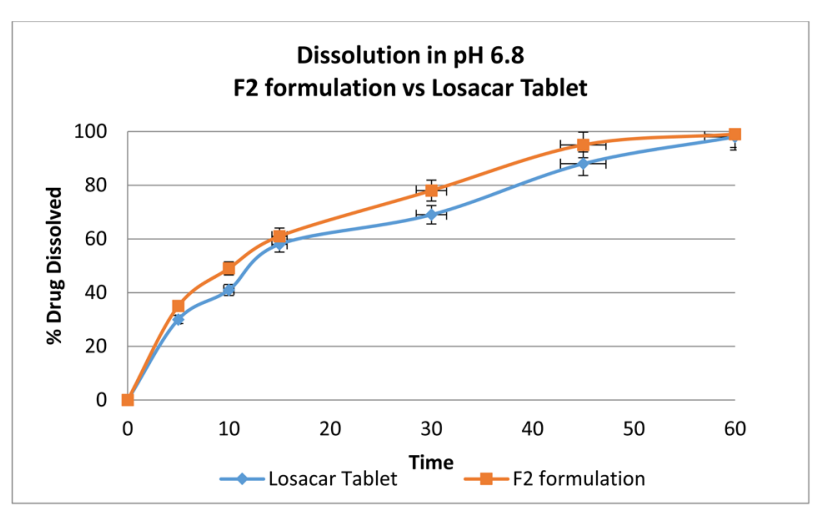

Fig. 15: Dissolution study in pH 6.8 and comparison with marketed product.

Table 10: Stability result of optimized formulation F2.

\begin{tabular}{|c|c|c|c|c|c|}
\hline Condition & $\begin{array}{l}\text { Avg. wt (mg) } \\
(N=20)\end{array}$ & $\begin{array}{l}\text { Hardness (Kp) } \\
\quad(\mathrm{N}=10)\end{array}$ & $\begin{array}{c}\text { DT (Min) } \\
(\mathrm{N}=6)\end{array}$ & $\begin{array}{l}\text { Moisture Content } \\
(\text { LOD \%w/w) }\end{array}$ & Assay (\%) \\
\hline $40^{\circ} \mathrm{C} / 75 \%$ RH-1M & 103.5 & 6.1 & 8 & 2.20 & 100.1 \\
\hline $30^{\circ} \mathrm{C} / 65 \%$ RH- $1 \mathrm{M}$ & 102.5 & 5.5 & 7 & 2.15 & 99.8 \\
\hline $25^{\circ} \mathrm{C} / 60 \%$ RH- $6 \mathrm{M}$ & 102.4 & 5.8 & 7 & 1.79 & 100.9 \\
\hline
\end{tabular}




\section{CONCLUSION}

As per the outcome of preformulation studies the API is having average radius $(\mathrm{r})<5$ (less than five) this value implies that Losartan API is not suitable for direct compression. It has been concluded from the study that the SeDeM expert system can be successfully applied for the prediction of suitability of material for direct compression. It gives accurate predictions about material behavior and response of the material was same as predicted by the SeDeM expert system. It provides information about shortcoming of the material to be processed by direct compression which can be rectified at a preformulation level to get a robust formulation that can be easily scaled up for commercial manufacturing. The SeDeM expert system also reduces the number of trials at a preformulation level to get produced by direct compression especially in the case of a high drug load. By developing a database of the excipients commonly used in pharmaceutical formulation, the material of the desired characteristics can be selected with particular characteristics. Application of SeDeM expert system in the formulation masked flow of API and lactose was choice of excipient for selecting in direct compression process. SeDeM may become very economical and time saving tool. In conclusion, it could be determined that formulation F2 was the optimized product, which possessed satisfactory results in SeDeM parameters and parameters for finished products. There are very low variations observed in all the physical and chemical tests performed. It was observed that the optimized losartan potassium tablets were pharmaceutically equivalent with the marketed product. Even after the period of one month exposure at various atmospheric conditions, formulation found stable at various stability test. Dissolution found good in water and $\mathrm{pH} 6.8$ compare to other dissolution medias with low variation.. IR formulation with losartan potassium drug has been developed using SeDeM technique, using this technique cost effective dosage form can be prepared as it lowers the number of trials and developed product will have scientific background as well.

\section{FINANCIAL SUPPORT AND SPONSORSHIP}

$$
\text { Nil. }
$$

\section{CONFLICT OF INTEREST}

All authors declares no conflict of interest.

\section{ACKNOWLEDGMENT}

We are thankful Dr Zahed Zaheer for providing institutional facility to carry out research work at Y.B. Chavan College of Pharmacy.

\section{REFERENCES}

Igor Lifshitz, Ilan Kor, Shalom Shabat "Process for preparing losartan potassium with improved flow ability" US 20040171843 A1, Sep 2,2004 .
Pilar P., Josep M.S., Montserrat M. Anew expert systems (SeDeM Diagram) for control batch powder formulation and pre formulation drug products. European Journal of Pharmaceutics and Biopharmaceutics. 2006; 64:351-359.

Josep M. Suñé Negre, Encarna García Montoya, Pilar Pérez Lozano, Johnny E. Aguilar Díaz, Manel Roig Carreras, Roser Fuster García, Montserrat Miñarro Carmona and Josep R. Ticó Grau. SeDeM Diagram: A New Expert System for the Formulation of Drugs in Solid Form, Expert Systems for Human, Materials and Automation, Prof. PetricÄ $f$ Vizureanu (Ed.), ISBN: 978-953-307-334-7: 17-34 (2011).

Raymond C Rowe, 2009 Handbook of excipient $6^{\text {th }}$ edition: Page no 200. RPS Publishing UK.

Rudy Bonfilio, Taciane Ferreira Mendonça, Gislaine Ribeiro Pereira e Magali Benjamim de Araújo" Losartan Potassium Dissolution Test for Drug Release Evaluation in Pharmaceutical Capsules Using Hplc and UV Spectrophotometry" Quim. Nova, Vol. 33, No. 2, 377-383, 2010.

Aguilar_Díaz, JE, García-Montoya E, Pérez-Lozano P, SuñéNegre JM, Miñarro M \& Ticó JR (2009). The use of the SeDeM Diagram expert system to determine the suitability of diluents-disintegrants for direct compression and their use in formulation of ODT. Eur J Pharm \& Biopharm, 73, pp. 414-423.

Imran Tadwee, Sadhana Shahi, Zahed Zaheer. Preformulation studies using lactose in development of solid oral dosage form: a graphical representation using SeDeM method. Int J Curr Pharm Res 2017;9(5):168172.

Inderbir Singh \& Pradeep Kumar "Preformulation Studies for Direct Compression Suitability of Cefuroxime Axetil and Paracetamol: A Graphical Representation Using Sedem Diagram" Acta Poloniae Pharmaceutica ñ Drug Research, Vol. 69 No. 1 pp. 87-93, 2012.

Shahi SR, Tadwee I. "SeDeM in Preformulation of Solid Oral Dosage Form: A Review" Advances in Applied and Pharnaceutical Sciences Journal 2017, 1(1);11-17.

Shahi S, Chate R, Dube A, Tadwee I. "Preformulation Studies for Direct Compression Suitability of Polyethylene Oxide in Development of Solid Oral Dosage Form: A Graphical Representation Using SeDeM Diagram" Advances in Applied and Pharmaceutical Sciences Journal 2017, $1(1) ; 33-39$.

Kumar M, Mandal V, Hemalatha S. "Detection of Metformin hydrochloride in a traditionally used Indian Herbal Drug for Antidiabetic: A Case Report International Journal of Pharma and Bio Sciences 2011, 2 (2); 307-313.

Pharmacopia US, National formulary (USP-NP 37) Published by United States pharmacopial authority 2016, United States of America.

ICH stability guidelines "Stability Testing of New Drug Substances and Products" Q1A (R2) 6 February 2003.

Khan A, Iqbal Z, Rehman Z, Nasir F, Khan A, Ismail M, Roohullah A, Mohammad A. "Application of SeDeM Expert system in formulation development of effervescent tablets by direct compression" Saudi Pharmaceutical Journal (2014) 22, 433-444.

How to cite this article:

Tadwee I, Shahi S. Formulation Development of Losartan Potassium Immediate Release Tablets and Process Optimization using SeDeM Expert System. J App Pharm Sci, 2018; 8(02): 033-043. 